\title{
Analysis of the vibration of pipes conveying fluid
}

\section{Y L Zhang, D G Gorman* and J M Reese}

Department of Engineering, University of Aberdeen, Scotland, UK

\begin{abstract}
The dynamic equilibrium matrix equation for a discretized pipe element containing flowing fluid is derived from the Lagrange principle, the Ritz method and consideration of the coupling between the pipe and fluid. The Eulerian approach and the concept of fictitious loads for kinematic correction are adopted for the analysis of geometrically non-linear vibration. The model is then deployed to investigate the vibratory behaviour of the pipe conveying fluid. The results for a long, simply supported, fluid-conveying pipe subjected to initial axial tensions are compared with experimentally obtained results and those from a linear vibration model.
\end{abstract}

Keywords: vibration, pipes conveying fluid, finite element method, fluid-structure interaction

\section{NOTATION}

$A_{\mathrm{p}}, A_{\mathrm{f}} \quad$ cross-sectional area of the pipe and fluid respectively

B linear strain-displacement matrix

$\mathbf{c}_{i}, \mathbf{C}^{t} \quad i$ th elemental and assembly damping matrix respectively

$D_{\mathrm{e}}, D_{\mathrm{i}} \quad$ external and internal diameters respectively

D symmetric stress-strain matrix

$e_{\lambda}, \boldsymbol{e}_{\mathrm{R}} \quad$ relative errors of eigenvectors and

displacements respectively

$\boldsymbol{e} \quad$ tensor field of strain of the pipe

$\boldsymbol{e}_{0} \quad$ vector of the initial strain composed of a static axial stretched strain, a temperature strain and a strain caused by pressurization $p_{0}$ within the pipe

E, EI Young's modulus and flexural rigidity respectively

$E_{\mathrm{e}} \quad$ energy of external forces on the fluid-pipe element

$E_{i} \quad$ strain energy of the pipe element

$\boldsymbol{f}_{i}^{1}, \boldsymbol{f}_{i}^{\mathrm{ld}} \quad i$ th elemental load and fictitious load vectors respectively

$\boldsymbol{F}^{t} \quad$ assembled force vector at time $t$

$G \quad$ shear modulus

$h_{i} \quad$ shape functions, $i=1,2, \ldots, 10$

I area moment of inertia of the pipe

$\mathbf{k}_{i}, \mathbf{K}^{t} \quad i$ th elemental and assembly fluid-pipe stiffness matrices respectively

$K$ shear coefficient $l, L \quad$ pipe elemental length and pipe length

$\mathbf{m}_{i}, \mathbf{M}^{t} \quad$ respectively

$\mathbf{m}_{i}, \mathbf{M}^{t} \quad i$ th elemental and assembly fluid-pipe mass matrices respectively

$m_{\mathrm{p}}, m_{\mathrm{f}} \quad$ pipe and fluid masses per unit length respectively

$\mathbf{m}_{\mathrm{p}}, \mathbf{m}_{\mathrm{f}} \quad$ pipe and fluid inertia force-acceleration matrices respectively

$\mathbf{N}$ matrix of shape functions

$\overline{\boldsymbol{p}}_{\mathrm{p}}, \overline{\boldsymbol{p}}_{\mathrm{f}} \quad$ vectors of the prescribed pipe and fluid boundary traction respectively

$\boldsymbol{r}, \boldsymbol{R} \quad$ vectors of elemental and global unknown generalized displacements respectively

$s \quad$ total number of elements

$t \quad$ time

$\mathbf{T}_{i} \quad$ coordinate transformation matrix of the $i$ th element, $i=1,2, \ldots, s$

$T_{0}, T \quad$ initial axial tension and axial tension of the pipe respectively

$\boldsymbol{T}_{0} \quad$ vector of initial axial force $=\left\{T_{0} \cos \varphi, 0, T_{0} \sin \varphi\right\}^{\mathrm{T}}$

$u, \varphi, w \quad$ displacement components in the $x, \varphi$ and $y$ directions respectively

$\boldsymbol{u}_{\mathrm{p}}, \boldsymbol{u}_{\mathrm{f}} \quad$ vector fields of the pipe and fluid displacements respectively, i.e.

$\boldsymbol{u}_{\mathrm{p}}=\{u, \varphi, w\}^{\mathrm{T}}, \boldsymbol{u}_{\mathrm{f}}=\left\{u_{\mathrm{f}}, \varphi_{\mathrm{f}}, w_{\mathrm{f}}\right\}^{\mathrm{T}}$

$\dot{\boldsymbol{u}}_{\mathrm{p}}, \dot{\boldsymbol{u}}_{\mathrm{f}} \quad$ vector fields of absolute velocity of the pipe and fluid element respectively

$\ddot{\boldsymbol{u}}_{\mathrm{p}}, \ddot{\boldsymbol{u}}_{\mathrm{f}} \quad$ vector fields of absolute acceleration of the pipe and fluid element respectively

$\boldsymbol{u}_{\mathrm{r}} \quad$ vector fields of fluid displacement relative to the pipe displacement $\boldsymbol{u}_{\mathrm{p}}$

$U, \boldsymbol{U} \quad$ scalar and vector fields of fluid velocity relative to the moving pipe respectively, i.e. $\boldsymbol{U}=\{U \cos \varphi, 0, U \sin \varphi\}^{\mathrm{T}}$ 


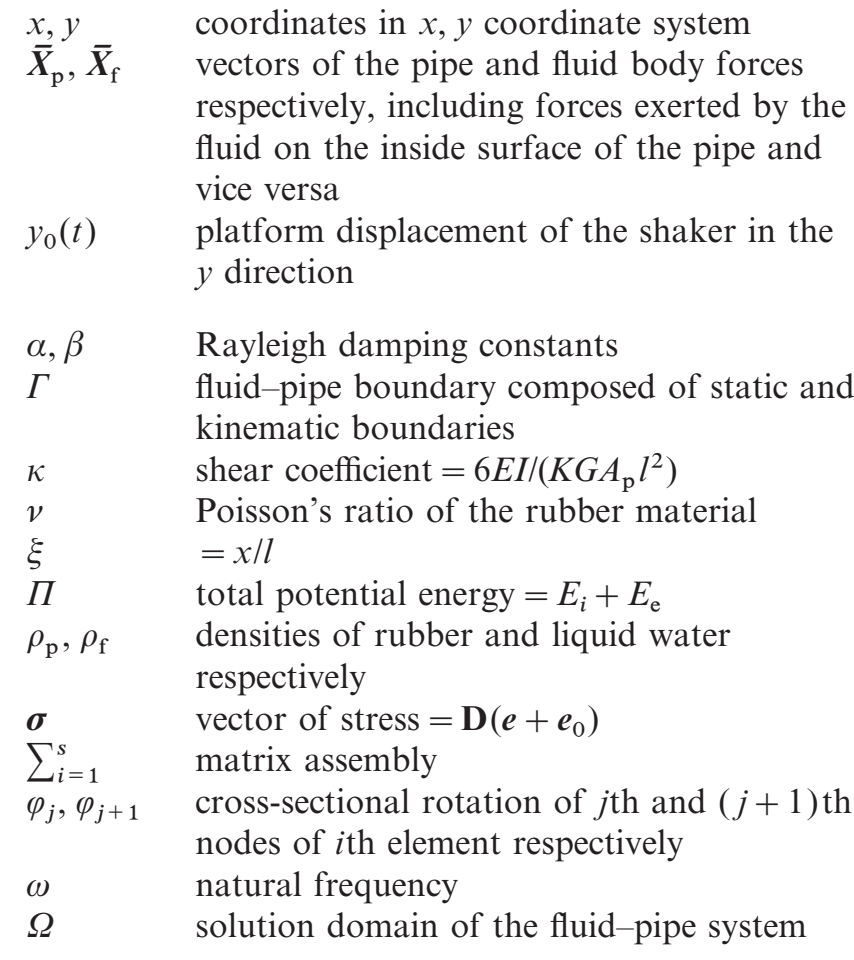

\section{Subscripts}

$i \quad$ elemental number

$n \quad$ vibration mode of the system

$\mathrm{p}, \mathrm{f} \quad$ pipe and fluid quantities respectively

$u, \varphi, w \quad$ quantities in the $x, \phi$ and $y$ directions respectively

eigenvalues of the system

\section{Superscripts}

$\begin{array}{ll}t & \text { time } \\ \mathrm{T} & \text { transpose of matrix }\end{array}$

\section{INTRODUCTION}

Over the past four decades the vibration of pipes conveying fluid has been studied extensively; an excellent overview is presented by Païdoussis and $\mathrm{Li} \mathrm{[1]}$. The linear vibration of the system has been understood for some time [2-9]. Linear models are found, however, to be in serious error when the fluid flow velocity approaches a critical value (leading to bifurcation of the dynamic response) [10] or the pipe performs large-amplitude vibration in which components of in-plane force (which are a function of the instantaneous vibration shape) have a marked effect. This latter effect is termed the geometric or membrane effect and is the subject of the benchmark paper by Holmes [11].

In recent years much effort has been devoted to assessing non-linear dynamic behaviour mainly by using analytical (see, for example, references [12] and [13]) and numerical methods such as finite difference and finite element methods [14]. However, numerical work on the non-linear vibration of pipes conveying fluid is quite limited. Lin and Tsai [15] extended the concept of fictitious loads $[16,17]$ to dynamic problems of pipes conveying fluid with the inclusion of shear deformation effects for the analysis of geometrically non-linear vibration. The deformation of the structures can be computed by iteratively updating the finite element nodal coordinates. As the in-plane kinematic corrections are asked for, it is unnecessary to formulate non-linear strain-displacement terms in the finite element model for the analysis of geometrically non-linear vibration. This finite element model, however, is not quite applicable to non-linear dynamic analysis of pipes conveying fluid that are subjected to various initial axial strain and transient flow within the pipes. Besides, in the previous finite element model, flowing fluid and moving pipes are only coupled weakly.

This paper presents a finite element model in which flowing fluid and moving pipes have been fully coupled using the Eulerian approach and the concept of fictitious loads for the kinematic corrections. This model is used for analysing the dynamic response of fluid-conveying pipes subjected to initial axial strains. These strains arise from initial stretch or compression, temperature and/or internal pressure. The effects of shear deformation and rotary inertia are also incorporated in the model, thus lending to the analysis of Timoshenko beams after linearizing the finite element formulation. The effect of initial axial strain and fluid flow on the dynamic behaviour of the system is analysed. Numerical examples are given in order to verify its utility and are compared with experiment.

\section{BASIC ASSUMPTIONS AND DESCRIPTION OF THE SYSTEM}

The system to be studied (Fig. 1) consists of a circular pipe, simply supported and pinned at both ends, of length $L$, cross-sectional area $A_{\mathrm{p}}$, mass per unit length $m_{\mathrm{p}}$ and flexural rigidity $E I$, conveying a fluid of mass $m_{\mathrm{f}}$ per unit length with axial flow velocity $U$ and pressure $p$. The initial, constant axial tension over the length of the pipe is $T_{0}$.

The general assumptions made in the course of the analysis of the system are as follows:

1. The pipe is composed of a linear, homogeneous and isotropic elastic material.

2. The fluid is incompressible.

3. The velocity profile of the fluid is uniform.

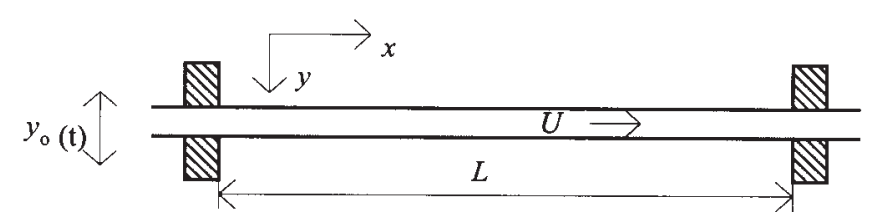

Fig. 1 Schematic of the system under consideration 
4. The diameter of the pipe is much smaller than its length.

5. The motion of the pipe is planar.

6. There is no axial or lateral motion at either end of the pipe.

Let coordinate $x$ be in the axis at static equilibrium and coordinate $y$ be normal to it.

\section{MODEL DEVELOPMENT}

\subsection{Order of magnitude analysis}

As the effect of large vibration (or geometric nonlinearity) of pipes conveying fluid will be examined, it is useful to perform an order of magnitude analysis. Recalling the assumption that the motion of the pipe is planar, it is assumed that the lateral displacement $w$ in the $y$ direction is 'small' compared with the length of the pipe, i.e.

$$
w(y) / L \sim O(\varepsilon)
$$

where $\varepsilon \ll 1$.

It is known that, in the governing matrix equations for large vibration, terms of higher order than that for small vibration exist. Thus, if the governing matrix equations are of even order, terms of $O\left(\varepsilon^{2}\right)$ have to be present in the equations. Therefore, all expressions in the equations presented in this paper have to be exact to $O\left(\varepsilon^{3}\right)$ before any simplification can be undertaken. It can also be shown (see, for example, reference [18]) that longitudinal displacements, $u$ in the $x$ direction, and the rotational displacement $\varphi$ are given by

$$
\begin{aligned}
& u(x) / L \sim O\left(\varepsilon^{2}\right) \\
& \varphi \sim O(\varepsilon)
\end{aligned}
$$

Therefore, a displacement vector can be defined as $\boldsymbol{u}=\{u / L, \varphi, w / L\} \sim \boldsymbol{O}(\varepsilon)$.

\subsection{Dynamic equilibrium equation}

The principle of minimum potential energy, as described by the Lagrange principle, can be applied to fluid-pipe vibration interaction and formulated to model the deformed fluid-pipe elements into which the system is discretized as follows (see, for example, reference [19]):

$$
\Pi=E_{i}+E_{\mathrm{e}}=\text { minimum }
$$

where

$$
\begin{aligned}
E_{i}= & \frac{1}{2} \int_{\Omega}\left(\boldsymbol{e}+\boldsymbol{e}_{0}\right) \mathbf{D}\left(\boldsymbol{e}+\boldsymbol{e}_{0}\right) \mathrm{d} \Omega \\
E_{\mathrm{e}}= & -\int_{\Omega} \boldsymbol{u}_{\mathrm{p}}^{\mathrm{T}} \overline{\boldsymbol{X}}_{\mathrm{p}} \mathrm{d} \Omega-\int_{\Omega} \boldsymbol{u}_{\mathrm{f}}^{\mathrm{T}} \overline{\boldsymbol{X}}_{\mathrm{f}} \mathrm{d} \Omega \\
& -\int_{\Gamma_{\mathrm{p}}} \boldsymbol{u}_{\mathrm{p}}^{\mathrm{T}} \overline{\boldsymbol{p}}_{\mathrm{p}} \mathrm{d} \Gamma-\int_{\Gamma_{\mathrm{p}}} \boldsymbol{u}_{\mathrm{f}}^{\mathrm{T}} \overline{\boldsymbol{p}}_{\mathrm{f}} \mathrm{d} \Gamma
\end{aligned}
$$

C04498 @ IMechE 1999 in which $\mathbf{D}$ is a symmetric stress-strain matrix:

$$
\mathbf{D}=\left[\begin{array}{ccc}
E A_{\mathrm{p}} & 0 & 0 \\
0 & E I & 0 \\
0 & 0 & K G A_{\mathrm{p}}
\end{array}\right]
$$

Infinitesimal fluid-pipe elements, to which the Lagrange principle may be applied, may be separated into pipe elements and fluid elements. For the function $\Pi$ defined by equation (1), functions are required that are continuous in the solution domain $\Omega$ and, when appropriately combined, can satisfy the kinematic boundary conditions on $\Gamma_{u}$. A pipe element with two nodes and three degrees of freedom per node is shown in Fig. 2.

The approximate solution of the pipe displacement is sought in the matrix form of the shape functions, i.e.

$$
\boldsymbol{u}_{\mathrm{p}}=\{u, \varphi, w\}^{\mathrm{T}}=\boldsymbol{u}_{0}+\mathbf{N} \boldsymbol{r}
$$

where $\boldsymbol{u}_{0}$ are the functions constructed such that they satisfy the prescribed kinematic boundary conditions, i.e. $\boldsymbol{u}_{0}=\left\{0,0, y_{0}(t)\right\}^{\mathrm{T}}$,

$$
\boldsymbol{r}=\left\{u_{1}, w_{1}, \varphi_{1}, u_{2}, w_{2}, \varphi_{2}\right\}^{\mathrm{T}}
$$

and

$$
\mathbf{N}=\left[\begin{array}{cccccc}
h_{1} & 0 & 0 & h_{2} & 0 & 0 \\
0 & h_{3} & h_{4} & 0 & h_{5} & h_{6} \\
0 & h_{7} & h_{8} & 0 & h_{9} & h_{10}
\end{array}\right]
$$

Comparing equations (2), (3) and (4) leads to

$$
u=\mathbf{N}_{u} \boldsymbol{r}, \quad \varphi=\mathbf{N}_{\varphi} \boldsymbol{r} \quad \text { and } \quad w=y_{0}(t)+\mathbf{N}_{w} \boldsymbol{r}
$$

in which

$$
\begin{aligned}
& \mathbf{N}_{u}=\left[\begin{array}{llllll}
h_{1} & 0 & 0 & h_{2} & 0 & 0
\end{array}\right] \\
& \mathbf{N}_{\varphi}=\left[\begin{array}{llllll}
0 & h_{3} & h_{4} & 0 & h_{5} & h_{6}
\end{array}\right] \\
& \mathbf{N}_{w}=\left[\begin{array}{llllll}
0 & h_{7} & h_{8} & 0 & h_{9} & h_{10}
\end{array}\right]
\end{aligned}
$$

Matrix $\mathbf{N}$ contains the shape functions $h_{i}$ corresponding

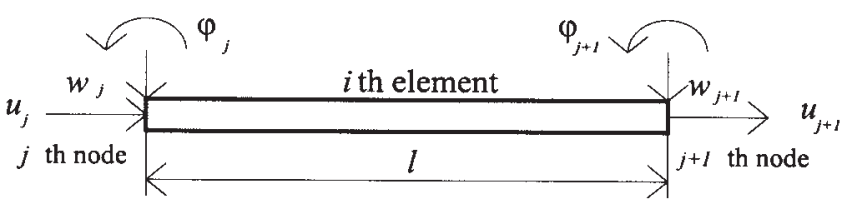

Fig. 2 Two-node pipe element with three degrees of freedom per node $(u, \varphi$ and $w)$ 
to the individual nodal parameters, namely

$$
\begin{aligned}
& h_{1}=1-\xi \\
& h_{2}=\xi \\
& h_{3}=\frac{6\left(\xi-\xi^{2}\right)}{l(1+2 \kappa)} \\
& h_{4}=\frac{(1+2 \kappa)-2(2+\kappa) \xi-3 \xi^{2}}{1+2 \kappa} \\
& h_{5}=\frac{6\left(-\xi+\xi^{2}\right)}{l(1+2 \kappa)} \\
& h_{6}=\frac{-2(1-\kappa) \xi+3 \xi^{2}}{1+2 \kappa} \\
& h_{7}=\frac{(1+2 \kappa)-2 \kappa \xi-3 \xi^{2}+2 \xi^{3}}{1+2 \kappa} \\
& h_{8}=\frac{l\left[-(1+\kappa) \xi+(2+\kappa) \xi^{2}-3 \xi^{3}\right]}{1+2 \kappa} \\
& h_{9}=\frac{2 \kappa \xi+3 \xi^{2}-2 \xi^{3}}{1+2 \kappa} \\
& h_{10}=\frac{l\left[\kappa \xi+(1-\kappa) \xi^{2}-\xi^{3}\right]}{1+2 \kappa}
\end{aligned}
$$

If it is assumed that the deformed curvature can be approximated by the second derivative of the flexural displacement, then the strain field in terms of the infinitesimal and large displacements may be represented by (see, for example, reference [20])

$$
\boldsymbol{e}=\boldsymbol{e}_{L}+\boldsymbol{e}_{N L}
$$

in which

$$
\begin{aligned}
\boldsymbol{e}_{L} & =\left\{\frac{\partial u}{\partial x}, \frac{\partial \varphi}{\partial x}, \varphi+\frac{\partial w}{\partial x}\right\}^{\mathrm{T}}=\mathbf{B} \boldsymbol{r} \\
\boldsymbol{e}_{N L} & =\left\{\frac{1}{2}\left(\frac{\partial w}{\partial x}\right)^{2}, 0,0\right\}^{\mathrm{T}}
\end{aligned}
$$

The matrix $\mathbf{B}$ is

$$
\begin{aligned}
& \mathbf{B}= \\
& {\left[\begin{array}{cccccc}
\frac{\mathrm{d} h_{1}}{\mathrm{~d} x} & 0 & 0 & \frac{\mathrm{d} h_{2}}{\mathrm{~d} x} & 0 & 0 \\
0 & \frac{\mathrm{d} h_{3}}{\mathrm{~d} x} & \frac{\mathrm{d} h_{4}}{\mathrm{~d} x} & 0 & \frac{\mathrm{d} h_{5}}{\mathrm{~d} x} & \frac{\mathrm{d} h_{6}}{\mathrm{~d} x} \\
0 & h_{3}+\frac{\mathrm{d} h_{7}}{\mathrm{~d} x} & h_{4}+\frac{\mathrm{d} h_{8}}{\mathrm{~d} x} & 0 & h_{5}+\frac{\mathrm{d} h_{9}}{\mathrm{~d} x} & h_{6}+\frac{\mathrm{d} h_{10}}{\mathrm{~d} x}
\end{array}\right]}
\end{aligned}
$$

The vector field of the fluid displacement is decomposed into two parts. One of these is the vector field of the pipe displacement $\boldsymbol{u}_{\mathrm{p}}$, the other is the vector field of the fluid displacement relative to the pipe $\boldsymbol{u}_{\mathrm{r}}$, which is equal to $\boldsymbol{U} t$, and therefore

$$
\boldsymbol{u}_{\mathrm{f}}=\boldsymbol{u}_{\mathrm{p}}+\boldsymbol{u}_{\mathrm{r}}
$$

Substitution of equation (2) in (8) results in

$$
\boldsymbol{u}_{\mathrm{f}}=\boldsymbol{u}_{0}+\mathbf{N} \boldsymbol{r}+\boldsymbol{u}_{\mathrm{r}}
$$

Using the theory of linear elasticity, the constitutive relation for a one-dimensional stress-strain beam can be written in matrix form as

$$
\boldsymbol{\sigma}=\mathbf{D}\left(e+e_{0}\right)
$$

Substituting equations (2) and (6) to (9) in equation (1), the function $\Pi$ may be expressed as

$$
\begin{aligned}
\Pi= & \frac{1}{2} \int_{\Omega}\left(\mathbf{B} \boldsymbol{r}+\boldsymbol{e}_{N L}+\boldsymbol{e}_{0}\right)^{\mathrm{T}} \mathbf{D}\left(\mathbf{B} \boldsymbol{r}+\boldsymbol{e}_{N L}+\boldsymbol{e}_{0}\right) \mathrm{d} \Omega \\
& -\int_{\Omega}\left(\boldsymbol{u}_{0}^{\mathrm{T}}+\boldsymbol{r}^{\mathrm{T}} \mathbf{N}^{\mathrm{T}}\right) \overline{\boldsymbol{X}}_{\mathrm{p}} \mathrm{d} \Omega \\
& -\int_{\Omega}\left(\boldsymbol{u}_{0}^{\mathrm{T}}+\boldsymbol{r}^{\mathrm{T}} \mathbf{N}^{\mathrm{T}}+\boldsymbol{u}_{\mathrm{r}}^{\mathrm{T}}\right) \overline{\boldsymbol{X}}_{\mathrm{f}} \mathrm{d} \Omega \\
& -\int_{\Gamma_{\mathrm{p}}}\left(\boldsymbol{u}_{0}^{\mathrm{T}}+\boldsymbol{r}^{\mathrm{T}} \mathbf{N}^{\mathrm{T}}\right) \overline{\boldsymbol{p}}_{\mathrm{p}} \mathrm{d} \Gamma \\
& -\int_{\Gamma_{\mathrm{p}}}\left(\boldsymbol{u}_{0}^{\mathrm{T}}+\boldsymbol{r}^{\mathrm{T}} \mathbf{N}^{\mathrm{T}}+\boldsymbol{u}_{\mathrm{r}}^{\mathrm{T}}\right) \overline{\boldsymbol{p}}_{\mathrm{f}} \mathrm{d} \Gamma
\end{aligned}
$$

A necessary condition for the minimum of the function $\Pi$ of multiple variables is that the first partial derivatives with respect to all the variables must be zero, which in the matrix notation implies

$$
\frac{\partial \Pi}{\partial \boldsymbol{r}}=\mathbf{0}
$$

This condition is applied to equation (11) for $\Pi$, and then the Lagrange principle is extended to dynamic problems (see, for example, reference [19]) by adding the inertia forces of the pipe and fluid into the second and third integral terms on the right-hand side of equation (11). The following set of non-linear algebraic equations are obtained after manipulation, and assuming that the difference in pressure between the inlet and outlet of the pipe is small compared with the inlet pressure:

$$
\begin{aligned}
\int_{\Omega} & \mathbf{B}^{\mathrm{T}} \mathbf{D}\left(\mathbf{B} \boldsymbol{r}+\boldsymbol{e}_{0}\right) \mathrm{d} \Omega+T_{0} \int_{\Omega} \mathbf{N}_{w}^{\prime \mathrm{T}} \mathbf{N}_{w}^{\prime} \boldsymbol{r} \mathrm{d} \Omega \\
+ & \int_{\Omega}\left(\mathbf{B}^{\mathrm{T}} \mathbf{D} \mathbf{B}_{N L}+\mathbf{B}_{N L}^{\mathrm{T}} \mathbf{D B}+\mathbf{B}_{N L}^{\mathrm{T}} \mathbf{D} \mathbf{B}_{N L}\right) \boldsymbol{r} \mathrm{d} \Omega \\
- & \int_{\Omega}\left[\mathbf{N}^{\mathrm{T}}\left(\overline{\boldsymbol{X}}_{\mathrm{p}}-\mathbf{m}_{\mathrm{p}} \ddot{\boldsymbol{u}}_{\mathrm{p}}\right)+\mathbf{N}^{\mathrm{T}}\left(\overline{\boldsymbol{X}}_{\mathrm{f}}-\mathbf{m}_{\mathrm{f}} \ddot{\boldsymbol{u}}_{\mathrm{f}}\right)\right] \mathrm{d} \Omega \\
- & \int_{\Gamma} \mathbf{N}^{\mathrm{T}}\left(\overline{\boldsymbol{p}}_{\mathrm{p}}+\overline{\boldsymbol{p}}_{\mathrm{f}}\right) \mathrm{d} \Gamma=0
\end{aligned}
$$

where

$$
\mathbf{m}_{\mathrm{p}}=\left[\begin{array}{ccc}
m_{\mathrm{p}} & 0 & 0 \\
0 & \rho_{\mathrm{p}} I & 0 \\
0 & 0 & m_{\mathrm{p}}
\end{array}\right]
$$


is the pipe inertia force-acceleration matrix,

$$
\mathbf{m}_{\mathrm{f}}=\left[\begin{array}{ccc}
m_{\mathrm{f}} & 0 & 0 \\
0 & \rho_{\mathrm{f}} I_{\mathrm{f}} & 0 \\
0 & 0 & m_{\mathrm{f}}
\end{array}\right]
$$

is the fluid inertia force-acceleration matrix,

$$
\mathbf{B}_{N L}=[1,0,0]^{\mathrm{T}} \frac{\partial w}{\partial x} \mathbf{N}_{w}^{\prime}
$$

is dependent on the displacement and (") represents the second-order substantial derivative with respect to time; the prime denotes a derivative with respect to $x$.

Fluid-structure interaction mechanisms are represented by the forces exerted by the flowing fluid within the pipe on the pipe wall, and vice versa. At the interface where the fluid and pipe are coupled, the vector field of the pipe element displacement is equal to that of the flowing fluid element displacement normal to the vector field of fluid relative velocity, $\boldsymbol{U}$. The vector field of the generalized pipe velocity and acceleration can be expressed as

$$
\dot{\boldsymbol{u}}_{\mathrm{p}}=\frac{\partial \boldsymbol{u}_{\mathrm{p}}}{\partial t} \quad \text { and } \quad \ddot{\boldsymbol{u}}_{\mathrm{p}}=\frac{\partial^{2} \boldsymbol{u}_{\mathrm{p}}}{\partial t^{2}}
$$

By differentiating both sides of equation (8), the following expressions describing the fluid velocity and acceleration vectors are obtained:

$$
\begin{aligned}
\dot{\boldsymbol{u}}_{\mathrm{f}}= & \frac{\partial \boldsymbol{u}_{\mathrm{p}}}{\partial t}+U \frac{\partial \boldsymbol{u}_{\mathrm{p}}}{\partial x}+\boldsymbol{U}+\boldsymbol{O}\left(\varepsilon^{3}\right) \\
\ddot{\boldsymbol{u}}_{\mathrm{f}}= & \frac{\partial^{2} \boldsymbol{u}_{\mathrm{p}}}{\partial t^{2}}+2 U \frac{\partial^{2} \boldsymbol{u}_{\mathrm{p}}}{\partial x \partial t}+U^{2} \frac{\partial^{2} \boldsymbol{u}_{\mathrm{p}}}{\partial x^{2}}+\frac{\partial U}{\partial t} \frac{\partial \boldsymbol{u}_{\mathrm{p}}}{\partial x} \\
& +\dot{\boldsymbol{U}}+\boldsymbol{O}\left(\varepsilon^{3}\right)
\end{aligned}
$$

Differentiation of equation (2) partially with respect to $t$ and $x$ gives

$$
\begin{aligned}
& \frac{\partial \boldsymbol{u}_{\mathrm{p}}}{\partial t}=\frac{\partial \boldsymbol{u}_{0}}{\partial t}+\mathbf{N} \dot{\boldsymbol{r}}, \quad \frac{\partial^{2} \boldsymbol{u}_{\mathrm{p}}}{\partial t^{2}}=\frac{\partial^{2} \boldsymbol{u}_{0}}{\partial t^{2}}+\mathbf{N} \ddot{\boldsymbol{r}} \\
& \frac{\partial \boldsymbol{u}_{\mathrm{p}}}{\partial x}=\mathbf{N}^{\prime} \boldsymbol{r}, \quad \frac{\partial^{2} \boldsymbol{u}_{\mathrm{p}}}{\partial x \partial t}=\mathbf{N}^{\prime} \dot{\boldsymbol{r}} \\
& \frac{\partial^{2} \boldsymbol{u}_{\mathrm{p}}}{\partial x^{2}}=\mathbf{N}^{\prime \prime} \boldsymbol{r}
\end{aligned}
$$

Similarly, it can be shown that

$$
\dot{\boldsymbol{U}}=U\left(\begin{array}{l}
0 \\
0 \\
1
\end{array}\right) \mathbf{N}_{w}^{\prime} \dot{\boldsymbol{r}}+\frac{\partial U}{\partial t}\left(\begin{array}{l}
1 \\
0 \\
0
\end{array}\right)+\frac{\partial U}{\partial t}\left(\begin{array}{l}
0 \\
0 \\
1
\end{array}\right) \mathbf{N}_{w}^{\prime} \boldsymbol{r}
$$

In this analysis, the Eulerian approach is used to update the coordinates iteratively and also to reform the stiffness matrix iteratively. This enables geometrically non-linear vibration to be analysed while ignoring the third integral term on the left-hand side of equation (13), which is known as the initial displacement matrix due to large deformation. In the course of the iteration, the concept of fictitious loads has to be applied to equation (13) on the basis of the in-plane kinematic corrections due to large deformation. Substituting equations (14) to (16) in (13), applying Green's theorem on the second-order terms with respect to $x$ (which also serves to reduce the order of the governing equation) and then transforming local coordinates into global ones by using the coordinate transformation matrix

$$
\mathbf{T}_{i}=\left[\begin{array}{cccccc}
\cos \varphi_{j} & -\sin \varphi_{j} & 0 & 0 & 0 & 0 \\
\sin \varphi_{j} & \cos \varphi_{j} & 0 & 0 & 0 & 0 \\
0 & 0 & 1 & 0 & 0 & 0 \\
0 & 0 & 0 & \cos \varphi_{j+1} & -\sin \varphi_{j+1} & 0 \\
0 & 0 & 0 & \sin \varphi_{j+1} & \cos \varphi_{j+1} & 0 \\
0 & 0 & 0 & 0 & 0 & 1
\end{array}\right]
$$

the following set of second-order differential equations is obtained:

$$
\begin{aligned}
\mathbf{T}_{i}^{\mathrm{T}}\left[\int_{\Omega} \mathbf{N}^{\mathrm{T}}\left(\mathbf{m}_{\mathrm{p}}+\mathbf{m}_{\mathrm{f}}\right) \mathbf{N} \mathrm{d} \Omega\right] \mathbf{T}_{i} \ddot{\boldsymbol{r}}+\mathbf{T}_{i}^{\mathrm{T}}\left[\int_{\Omega} \mathbf{N}^{\mathrm{T}}\left(2 \mathbf{m}_{\mathrm{f}} U\right) \mathbf{N}^{\prime} \mathrm{d} \Omega+\int_{\Omega} \mathbf{N}_{w}^{\mathrm{T}}\left(m_{\mathrm{f}} U\right) \mathbf{N}_{w}^{\prime} \mathrm{d} \Omega\right] \mathbf{T}_{i} \dot{\boldsymbol{r}} \\
+\mathbf{T}_{i}^{\mathrm{T}}\left[\int_{\Omega} \mathbf{B}^{\mathrm{T}} \mathbf{D B} \mathrm{d} \Omega+\int_{\Omega} \mathbf{N}_{w}^{\prime \mathrm{T}}\left(T_{0}\right) \mathbf{N}_{w}^{\prime} \mathrm{d} \Omega-\int_{\Omega} \mathbf{N}^{\prime \mathrm{T}}\left(\mathbf{m}_{\mathrm{f}} U^{2}\right) \mathbf{N}^{\prime} \mathrm{d} \Omega\right] \mathbf{T}_{i} \boldsymbol{r} \\
+\mathbf{T}_{i}^{\mathrm{T}}\left[\int_{\Omega} \mathbf{N}^{\mathrm{T}}\left(\mathbf{m}_{\mathrm{f}} \dot{U}\right) \mathbf{N}^{\prime} \mathrm{d} \Omega+\int_{\Omega} \mathbf{N}_{w}^{\mathrm{T}}\left(m_{\mathrm{f}} \dot{U}\right) \mathbf{N}_{w}^{\prime} \mathrm{d} \Omega\right] \mathbf{T}_{i} \boldsymbol{r} \\
=\mathbf{T}_{i}^{\mathrm{T}}\left[-\int_{\Omega} \mathbf{B}^{\mathrm{T}} \mathbf{D} \boldsymbol{e}_{0} \mathrm{~d} \Omega+\int_{\Omega} \mathbf{N}^{\mathrm{T}}\left(\overline{\boldsymbol{X}}_{\mathrm{p}}+\overline{\boldsymbol{X}}_{\mathrm{f}}\right) \mathrm{d} \Omega+\int_{\Gamma_{\mathrm{p}}} \mathbf{N}^{\mathrm{T}}\left(\overline{\boldsymbol{p}}_{\mathrm{p}}+\overline{\boldsymbol{p}}_{\mathrm{f}}\right) \mathrm{d} \Gamma\right] \\
-\mathbf{T}_{i}^{\mathrm{T}}\left[\int_{\Omega} \mathbf{N}_{u}^{\mathrm{T}}\left(m_{\mathrm{f}} \dot{U}\right) \mathrm{d} \Omega+\int_{\Omega} \mathbf{N}^{\mathrm{T}}\left(\mathbf{m}_{\mathrm{p}}+\mathbf{m}_{\mathrm{f}}\right) \ddot{\boldsymbol{i}}_{0} \mathrm{~d} \Omega\right]+\boldsymbol{f}_{i}^{\mathrm{ld}}
\end{aligned}
$$


This can be rewritten in the standard form

$$
\mathbf{m}_{i} \ddot{\boldsymbol{r}}+\mathbf{c}_{i} \dot{\boldsymbol{r}}+\mathbf{k}_{i} \boldsymbol{r}=\boldsymbol{f}_{i}^{1}+\boldsymbol{f}_{i}^{\mathrm{ld}}
$$

in which individual symbols have the following meaning:

$$
\mathbf{m}_{i}=\mathbf{T}_{i}^{\mathrm{T}}\left[\int_{\Omega} \mathbf{N}^{\mathrm{T}}\left(\mathbf{m}_{\mathrm{p}}+\mathbf{m}_{\mathrm{f}}\right) \mathbf{N} \mathrm{d} \Omega\right] \mathbf{T}_{i}
$$

is the $i$ th elemental fluid-pipe mass matrix in the global coordinate system,

$$
\mathbf{c}_{i}=\mathbf{T}_{i}^{\mathrm{T}}\left[2 U \int_{\Omega} \mathbf{N}^{\mathrm{T}} \mathbf{m}_{\mathrm{f}} \mathbf{N}^{\prime} \mathrm{d} \Omega+m_{\mathrm{f}} U \int_{\Omega} \mathbf{N}_{w}^{\mathrm{T}} \mathbf{N}_{w}^{\prime} \mathrm{d} \Omega\right] \mathbf{T}_{i}
$$

is the $i$ th elemental fluid flowing damping matrix in the global coordinate system,

$$
\begin{aligned}
\mathbf{k}_{i}=\mathbf{T}_{i}^{\mathrm{T}}\left[\int_{\Omega} \mathbf{B}^{\mathrm{T}} \mathbf{D B} \mathrm{d} \Omega-U^{2} \int_{\Omega} \mathbf{N}^{\prime \mathrm{T}} \mathbf{m}_{\mathrm{f}} \mathbf{N}^{\prime} \mathrm{d} \Omega\right. \\
\left.+T_{0} \int_{\Omega} \mathbf{N}_{w}^{\prime \mathrm{T}} \mathbf{N}_{w}^{\prime} \mathrm{d} \Omega\right] \mathbf{T}_{i} \\
+\mathbf{T}_{i}^{\mathrm{T}}\left[\dot{U} \int_{\Omega} \mathbf{N}^{\mathrm{T}} \mathbf{m}_{\mathrm{f}} \mathbf{N}^{\prime} \mathrm{d} \Omega+m_{\mathrm{f}} \dot{U} \int_{\Omega} \mathbf{N}_{w}^{\mathrm{T}} \mathbf{N}_{w}^{\prime} \mathrm{d} \Omega\right] \mathbf{T}_{i}
\end{aligned}
$$

is the $i$ th elemental fluid-pipe stiffness matrix consisting of the pipe stiffness and initial stress matrices and the flowing fluid stiffness matrix in the global coordinate system, and

$$
\begin{aligned}
\boldsymbol{f}_{i}^{1}=\mathbf{T}_{i}^{\mathrm{T}}\left[-\int_{\Omega} \mathbf{B}^{\mathrm{T}} \mathbf{D} \boldsymbol{e}_{0} \mathrm{~d} \Omega+\int_{\Omega} \mathbf{N}^{\mathrm{T}}\left(\overline{\boldsymbol{X}}_{\mathrm{p}}+\overline{\boldsymbol{X}}_{\mathrm{f}}\right) \mathrm{d} \Omega\right. \\
\left.+\int_{\Gamma} \mathbf{N}^{\mathrm{T}}\left(\overline{\boldsymbol{p}}_{\mathrm{p}}+\overline{\boldsymbol{p}}_{\mathrm{f}}\right) \mathrm{d} \Gamma\right] \\
+\mathbf{T}_{i}^{\mathrm{T}}\left[\int_{\Omega} \mathbf{N}^{\mathrm{T}}\left(\mathbf{m}_{\mathrm{p}}+\mathbf{m}_{\mathrm{f}}\right) \ddot{\boldsymbol{u}}_{\mathrm{o}} \mathrm{d} \Omega+m_{\mathrm{f}} \dot{U} \int_{\Omega} \mathbf{N}_{u}^{\mathrm{T}} \mathrm{d} \Omega\right]
\end{aligned}
$$

is the dynamic force acting upon the system in the global coordinate system.

The fictitious loads in the global coordinate system can be expressed as (see, for example, reference [15]):

$$
\boldsymbol{f}_{i}^{\mathrm{ld}}=\mathbf{T}_{i}^{\mathrm{T}} \mathbf{k}_{i}^{0} \boldsymbol{u}^{\mathrm{ld}}=\mathbf{T}_{i}^{\mathrm{T}}\left\{-a_{1}, 2 a_{2}, a_{2} l, a_{3},-2 a_{4}, a_{4} l\right\}^{\mathrm{T}}
$$

where

$$
\begin{aligned}
\mathbf{k}_{i}^{0}= & \int_{\Omega} \mathbf{B}^{\mathrm{T}} \mathbf{D B} \mathrm{d} \Omega, \boldsymbol{u}^{1 \mathrm{~d}} \\
= & \left\{0,0, \varphi_{j}-\sin \varphi_{j}, l\left(1-\cos \varphi_{j+1}\right),\right. \\
& \left.0, \varphi_{j+1}-\sin \varphi_{j+1}\right\}^{\mathrm{T}}
\end{aligned}
$$

Proc Instn Mech Engrs Vol 213 Part C

$$
\begin{aligned}
& a_{1}=A_{\mathrm{p}} E\left(1-\cos \varphi_{j}\right) \\
& a_{2}=\frac{6 E I\left(\varphi_{j}-\sin \varphi_{j}\right)}{l^{2}+12 E I / \kappa G A_{\mathrm{p}}} \\
& a_{3}=A_{\mathrm{p}} E\left(1-\cos \varphi_{j+1}\right) \\
& a_{4}=\frac{6 E I\left(\varphi_{j+1}-\sin \varphi_{j+1}\right)}{l^{2}+12 E I / \kappa G A_{\mathrm{p}}}
\end{aligned}
$$

The definition of $\mathbf{T}_{i}$ in equation (17), together with equations (5) and (20), shows that equation (18) is nonlinear for large deformation. This equation represents the generalized conditions of dynamic equilibrium of the discretized system element in the global coordinate system for analysis of geometrically non-linear vibration.

The governing equations (19) of the fluid-conveying pipe elements can be combined to form the assembly of the discretized system at any instant $t$ by considering the equilibrium and continuity of displacements at the interfaces between adjoining elements, i.e.

$$
\mathbf{M}^{t} \ddot{\boldsymbol{R}}+\mathbf{C}^{t} \dot{\boldsymbol{R}}+\mathbf{K}^{t} \boldsymbol{R}=\mathbf{F}^{t}
$$

In this equation $\mathbf{C}^{t}$ represents the total damping matrix, which is composed of two parts if Rayleigh damping within the pipe is taken into account, i.e.

$$
\mathbf{C}^{t}=\mathbf{C}_{\mathrm{f}}^{t}+\mathbf{C}_{\mathrm{s}}^{t}
$$

in which $\mathbf{C}_{\mathrm{f}}^{t}$ is due to translation and rotation of the fluid and $\mathbf{C}_{\mathrm{s}}^{t}$ is a linear combination of the mass and stiffness matrices $\mathbf{M}^{t}$ and $\mathbf{K}^{t}$, given by (see, for example, reference [21])

$$
\mathbf{C}_{\mathrm{s}}^{t}=\alpha \mathbf{M}^{t}+\beta \mathbf{K}^{t}
$$

The assembly equation of the discretized system can then be solved by the well-known Newmark method. The eigenproblems can be solved by the inverse iteration method. It should be noted that geometric non-linearity due to large deformation, rotary inertia and shear deformation are incorporated in this model. It can be seen that, when the vibration displacement is small, equation (21) reduces to the linear vibration problem. For large deformation the structural matrices and force vectors in equation (21) are dependent on the displacements $\boldsymbol{r}$. For small deformation, $\mathbf{T}_{i}$ and $\boldsymbol{f}_{i}^{\text {ld }}$ may be thought of as a unit diagonal matrix and a zero vector respectively. Therefore, this formulation can be used to solve both geometrically linear and non-linear dynamic problems. 'Natural frequencies' can be extracted from equation (21) for the small vibrations in which equation (21) becomes linear. Resonant frequencies can also be obtained within the non-linear regime by using an iteration method. This model can also be applied to pipes with different boundary conditions.

\section{EXPERIMENTAL SET-UP AND PROCEDURE}

Experiments were conducted using a closed-loop flow facility as shown schematically in Fig. 3. Steady flow was 


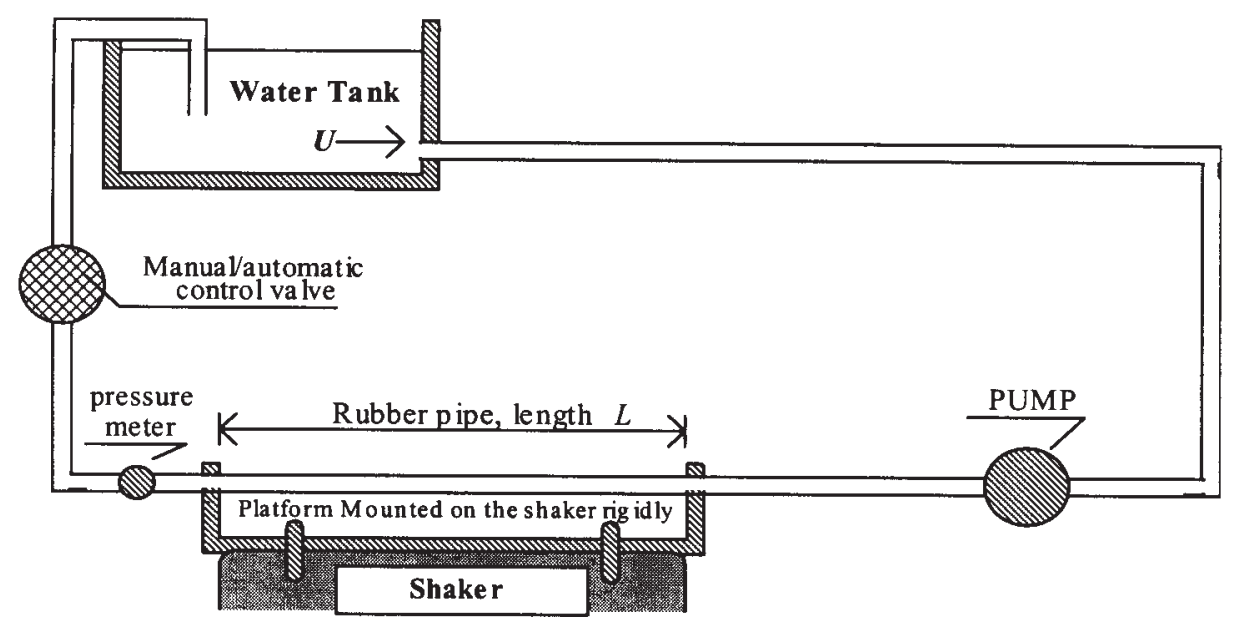

Fig. 3 Closed-loop flow experimental facility

produced using a centrifugal pump and a manual/ automatic control valve. The test section consisted of a circular rubber pipe simply supported and pinned at either end of a rigid platform. The complete assembly was clamped on to a shaker driven by an amplified sinewave signal from a $5 \mathrm{MHz}$ function generator. This method of fixing the pipe to the platform is sufficient to assume that simply supported boundary conditions apply at each end of the pipe.

The shaker excitation was measured by an accelerometer mounted on the shaker platform. The accelerometer signal was examined using an oscilloscope and a phase meter. A laser velocity transducer was used to measure the vibration response of the pipe. The laser was carefully aligned to focus its narrow beam at a small piece of retroreflective tape, which is attached to the surface of the mid-point of the pipe. Both signals were then passed to a real-time fast Fourier transform (FFT) analyser.

A schematic diagram of this measurement set-up is shown in Fig. 4. The sampling rate for all frequency readings was $1000 \mathrm{~Hz}$ and the total sampling time was $4.096 \mathrm{~s}$. The excitation and response signals from the laser velocity transducer and the accelerometer were treated and displayed on the oscilloscope screen simultaneously. Both signals were also input to the FFT analyser. The excitation frequency was adjusted until a stationary picture was obtained on the oscilloscope screen and the shift in phase between the two signals was $90^{\circ}$ in order to find the 'natural frequencies' and to record the amplitude of the responses and the frequency spectrum. This process was completed for various initial

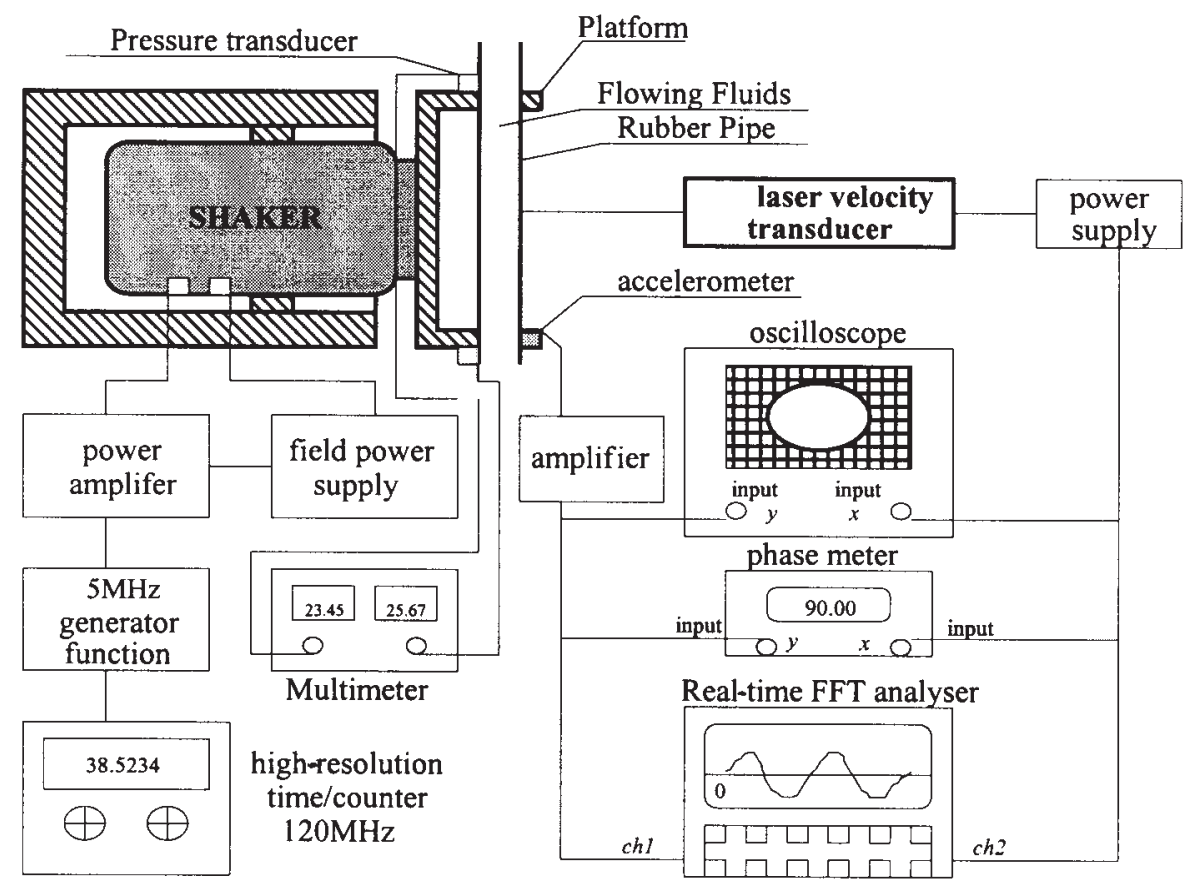

Fig. 4 Schematic diagram of the measurement equipment 


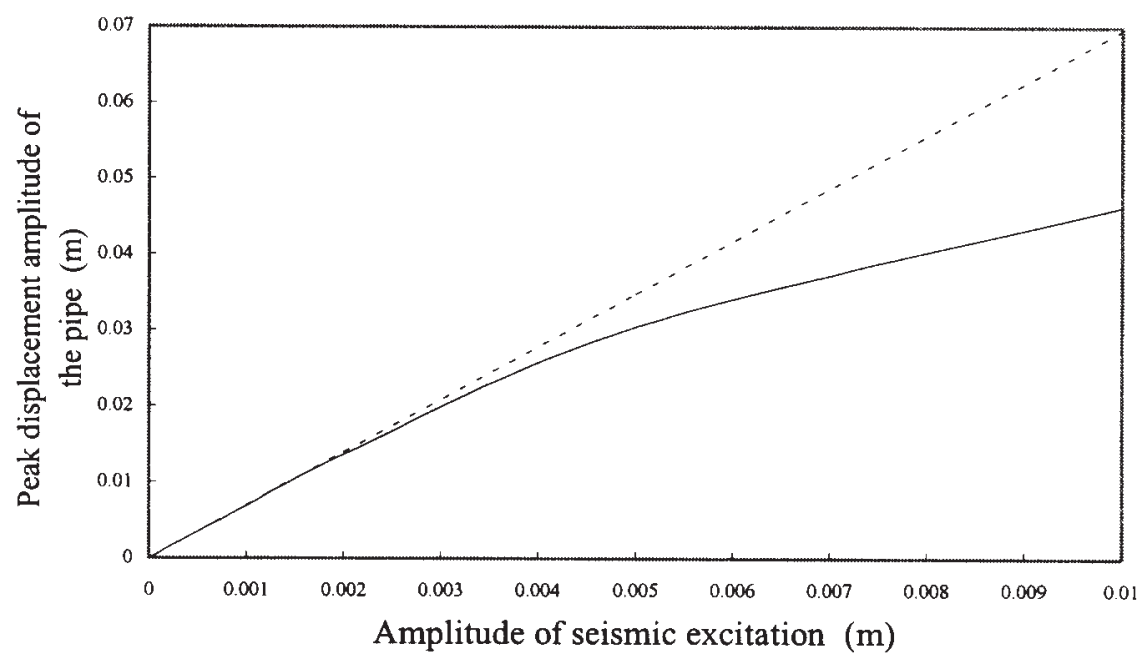

Fig. 5 Mid-point amplitude of the pipe versus amplitude of seismic excitation $\bar{y}_{0}$ : —— non-linear model; ..... linear model

axial tensions and flow velocities. Using this type of measurement it should be noted that, for the specific case where the fluid is not flowing in the pipe, the only modes that can be excited are the odd modes, i.e. 1, 3, 5 , 7, etc. When the fluid is flowing, all modes can be excited but the present measurement set-up allows only the odd modes to be observed.

\section{RESULTS}

The pipe conveying fluid (Fig. 3) was made of rubber and subjected to a vertical harmonic seismic support motion $y_{0}(t)=\bar{y}_{0} \sin \Omega t$, in which $\bar{y}_{0}$ represents the excitation amplitude. Simply supported boundary conditions were assumed. The pipe had external and internal diameters $D_{\mathrm{e}}=9.7 \times 10^{-3} \mathrm{~m}$ and $D_{i}=6.0 \times 10^{-3} \mathrm{~m}$ respectively and length $L=3.62 \times 10^{-1} \mathrm{~m}$. The Young's modulus $E=2.0924 \times 10^{6} \mathrm{~Pa}$, Poisson's ratio $v=0.5$, the density of the rubber $\rho_{\mathrm{p}}=1128.56 \mathrm{~kg} / \mathrm{m}^{3}$ and water density $\rho_{\mathrm{f}}=1000.00 \mathrm{~kg} / \mathrm{m}^{3}$. The pipe was modelled by 15 elements. The relative errors of the eigenvalues and the generalized displacements, used to check convergence, were less than $e_{\lambda}=10^{-4}$ and $\boldsymbol{e}_{R}=10^{-5} \boldsymbol{e}_{I}$ respectively, $e_{\lambda}$ and $e_{R}$ being defined as

$$
e_{\lambda}=\frac{\left|\lambda_{i+1}\right|-\left|\lambda_{i}\right|}{\left|\lambda_{i}\right|} \quad \text { and } \quad e_{R}=\frac{\left|\boldsymbol{R}^{j+1}\right|-\left|\boldsymbol{R}^{j}\right|}{\left|\boldsymbol{R}^{j}\right|}
$$

where $\lambda$ are the eigenvalues, subscripts $i+1$ and $i$ denote the present and the previous numbers of elements respectively, superscripts $j+1$ and $j$ represent the present and previous computed generalized displacements respectively and $\boldsymbol{e}_{I}$ is an $(n+1$ th)-order unit vector.

The pipe was subjected to various initial tensions. The vibration of the pipe in the absence of or while conveying fluid over a wide range of flow velocities was investigated theoretically and experimentally.
For the first, third and fifth 'natural frequencies', the comparisons between results from the present model, the linear model and experiment are discussed for two cases below. The linear vibration model is given in the Appendix.

It was assumed that the shear deformation of the rubber pipe could be neglected and so was not included in the present vibration model. Prior to investigating the effect of an axial tension and internal flow velocity on the vibrating behaviour of the pipe conveying fluid, the dynamic response of the system as a function of varying amplitudes of seismic excitation was investigated. The effect of amplitude of excitation on the mid-point amplitude of the pipe is shown in Fig. 5 at initial axial tension $T_{0}=7.63 \mathrm{~N}$ and internal flow velocity $U=7.19 \mathrm{~m} / \mathrm{s}$. The figure shows a comparison of results obtained by using linear theory (linearizing the present model) and nonlinear theory (the full present model). This figure shows the non-linear vibration response due to large vibration initiated at a seismic excitation displacement of $\bar{y}_{0}=$ $0.002 \mathrm{~m}$.

Figure 6 shows the amplitude/frequency response of the mid-point for a seismic excitation amplitude of $0.012 \mathrm{~m}$. The skew form of this response can be immediately recognized as indicating non-linear frequency response.

The experimental results are characterized by nonlinear behaviour only for the first mode and lower axial tensions. Linear vibration response is, however, predominant in most cases.

\subsection{Empty pipe}

Prior to discussing the coupled vibration modes of the pipe conveying fluid, attention will be focused upon the vibration modes of the pipe in the absence of fluid. The first, third and fifth natural frequencies are extracted 


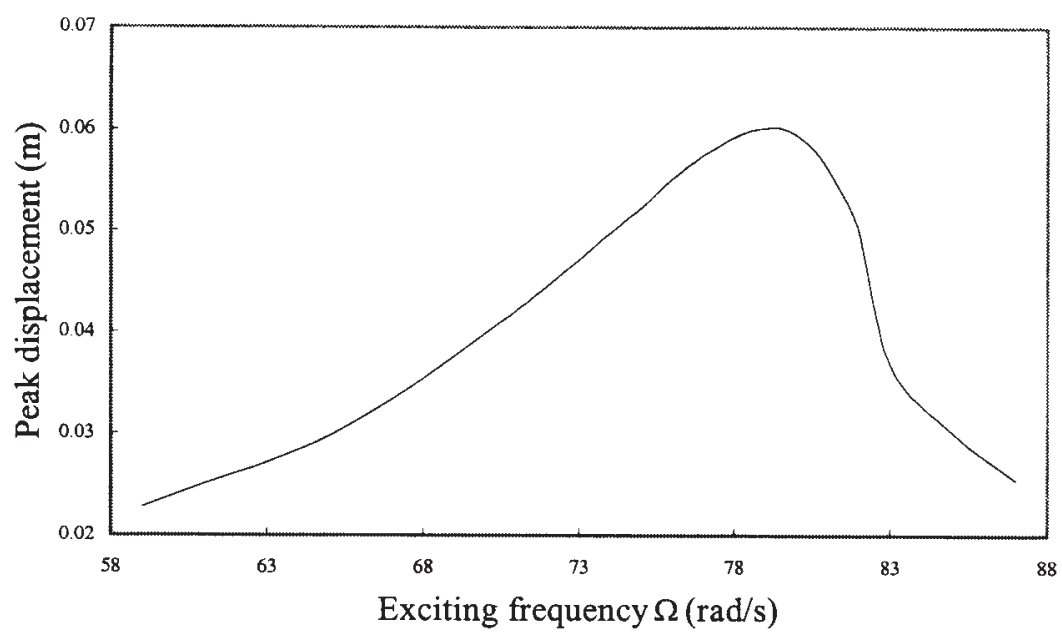

Fig. 6 Variation in peak displacement with exciting frequency $\Omega$ at $T_{0}=7.63 \mathrm{~N}, U=7.19 \mathrm{~m} / \mathrm{s}$ and $\bar{y}_{0}=$ $0.012 \mathrm{~m}$

both from the present model in the linear response region of Fig. 5 and from the linear vibration model given in the Appendix. Assessment of the effects of initial axial tensions on vibration modes are shown in Table 1.

The results indicate that the natural frequencies will increase as the initial axial tensions increase. For the first mode, natural frequencies obtained using the present model and the linear model are somewhat different from the experimental ones, but for the third or higher modes the theoretical values using the present model are much closer to experimental ones than those of the linear model.

\subsection{Pipe conveying fluid}

The effect of initial axial tensions and flow speed of the fluid on vibration modes in the linear response region are calculated. Table 2 shows the first, third and fifth natural frequencies at various initial axial tensions for a

Table 1 Comparison of theoretical results of natural frequencies with experimental results for the empty pipe

\begin{tabular}{|c|c|c|c|c|c|c|c|c|c|}
\hline \multirow{3}{*}{$\begin{array}{l}\text { Initial axial } \\
\text { tension } \\
T_{0}(\mathrm{~N})\end{array}$} & \multicolumn{9}{|c|}{ Natural frequencies $\omega_{n}{ }^{*}(\mathrm{~Hz})$} \\
\hline & \multicolumn{3}{|c|}{ Experimental } & \multicolumn{3}{|c|}{ Present model } & \multicolumn{3}{|c|}{ Linear (Appendix) } \\
\hline & $\omega_{1}$ & $\omega_{3}$ & $\omega_{5}$ & $\omega_{1}$ & $\omega_{3}$ & $\omega_{5}$ & $\omega_{1}$ & $\omega_{3}$ & $\omega_{5}$ \\
\hline 4.95 & 13.96 & 49.46 & 92.37 & 14.61 & 45.69 & 78.05 & 14.45 & 44.81 & 75.49 \\
\hline 7.63 & 18.65 & 59.38 & 106.74 & 17.83 & 53.80 & 89.84 & 16.87 & 52.44 & 86.07 \\
\hline 10.68 & & 69.08 & & & 62.11 & & & 60.68 & \\
\hline 12.43 & & 70.92 & & & 66.24 & & & 64.78 & \\
\hline 13.21 & 20.13 & 71.35 & & 23.06 & 67.97 & & 22.12 & 66.37 & \\
\hline 13.75 & & 74.88 & & & 69.13 & & & 67.71 & \\
\hline
\end{tabular}

* Subscript $n=1,3$ and 5 denotes the number of the vibration mode.

Table 2 Comparison of theoretical results of natural frequencies with experimental results for the pipe containing static fluid

\begin{tabular}{|c|c|c|c|c|c|c|c|c|c|}
\hline \multirow{3}{*}{$\begin{array}{l}\text { Initial axial } \\
\text { tension } \\
T_{0}(\mathrm{~N})\end{array}$} & \multicolumn{9}{|c|}{ Natural frequencies $\omega_{n}(\mathrm{~Hz})$} \\
\hline & \multicolumn{3}{|c|}{ Experimental } & \multicolumn{3}{|c|}{ Present model } & \multicolumn{3}{|c|}{ Linear (Appendix) } \\
\hline & $\omega_{1}$ & $\omega_{3}$ & $\omega_{5}$ & $\omega_{1}$ & $\omega_{3}$ & $\omega_{5}$ & $\omega_{1}$ & $\omega_{3}$ & $\omega_{5}$ \\
\hline 4.95 & 11.97 & 38.20 & 72.94 & 11.75 & 36.48 & 64.05 & 11.68 & 35.56 & 60.25 \\
\hline 7.63 & 14.56 & 45.41 & 83.15 & 14.37 & 44.33 & 77.73 & 14.37 & 44.05 & 74.31 \\
\hline 10.68 & & 52.04 & & & 50.48 & & & 51.98 & \\
\hline 12.43 & & 54.47 & & & 53.93 & & & 56.00 & \\
\hline 13.21 & & 55.22 & & & 55.38 & & & 57.69 & \\
\hline 13.75 & & 57.77 & & & 56.36 & & & 58.90 & \\
\hline
\end{tabular}


flow velocity $U=0.0$. In Fig. 7 the third natural frequencies are plotted against initial tensions.

Table 3 and Figs 8 to 10 show the comparisons of experimental results of vibration modes with theoretical ones, again in the linear response region, and the effect of flow speeds on the vibration modes of the pipe at initial axial tension $T_{0}=7.63 \mathrm{~N}$.
Figures 8 to 10 depict the first, third and fifth natural frequencies varying with flow velocity of the fluid. As expected, an increasing flow velocity has the effect of decreasing the natural frequencies. In general, for most frequencies the experimental results are higher than the calculated ones. This discrepancy may be mainly attributed to differences between the mathematical model

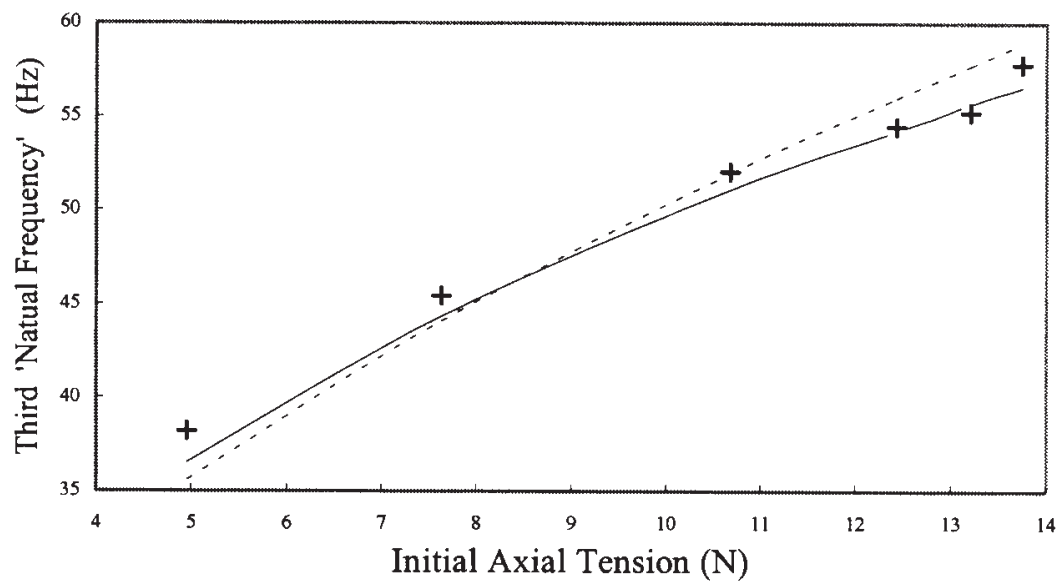

Fig. 7 Comparison of predicted third natural frequency with experiment at $U=0.0:+$ experimental result; - present model; $\cdots \cdots$ linear model

Table 3 Comparison of theoretical results of natural frequencies with experimental results for the pipe conveying fluid at initial axial tension $T_{0}=7.63 \mathrm{~N}$

\begin{tabular}{|c|c|c|c|c|c|c|c|c|c|}
\hline \multirow{3}{*}{$\begin{array}{l}\text { Flow } \\
\text { velocity } \\
U(\mathrm{~m} / \mathrm{s})\end{array}$} & \multicolumn{9}{|c|}{ Natural frequencies $\omega_{n}(\mathrm{~Hz})$} \\
\hline & \multicolumn{3}{|c|}{ Experimental } & \multicolumn{3}{|c|}{ Present model } & \multicolumn{3}{|c|}{ Linear (Appendix) } \\
\hline & $\omega_{1}$ & $\omega_{3}$ & $\omega_{5}$ & $\omega_{1}$ & $\omega_{3}$ & $\omega_{5}$ & $\omega_{1}$ & $\omega_{3}$ & $\omega_{5}$ \\
\hline 0.00 & 14.56 & 45.41 & 83.15 & 14.37 & 44.33 & 77.73 & 14.37 & 44.05 & 74.31 \\
\hline 1.54 & 14.26 & 44.35 & 81.02 & 14.27 & 44.06 & 77.37 & 14.21 & 43.67 & 73.70 \\
\hline 3.07 & 14.13 & 43.99 & 80.72 & 13.95 & 43.23 & 76.30 & 13.82 & 42.61 & 72.26 \\
\hline 4.34 & 13.66 & 43.35 & 79.95 & 13.51 & 42.13 & 74.86 & 13.27 & 40.98 & 70.18 \\
\hline 5.42 & 13.27 & 42.36 & 78.84 & 13.03 & 40.89 & 73.26 & 12.68 & 39.36 & 67.84 \\
\hline 6.43 & 12.92 & 41.98 & 77.70 & 12.48 & 39.48 & 71.43 & 12.02 & 37.45 & 65.15 \\
\hline 7.19 & 12.53 & 41.20 & 75.86 & 12.20 & 38.25 & 69.84 & 11.44 & 35.80 & 62.79 \\
\hline
\end{tabular}

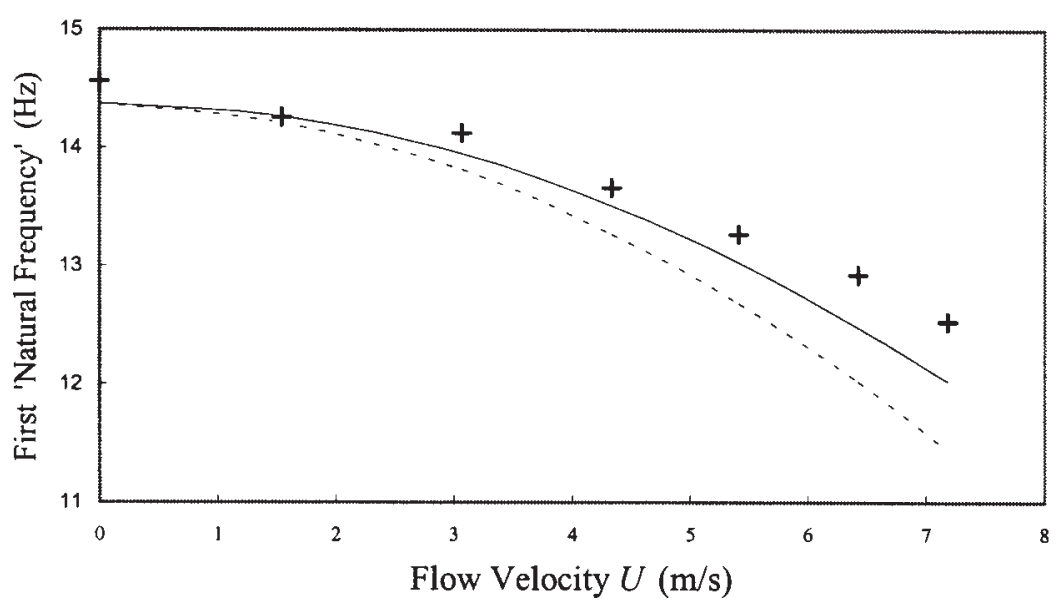

Fig. 8 Comparison of predicted first natural frequency with experiment at $T_{0}=7.63 \mathrm{~N}$ : + experimental result; $\_$present model; $\cdots \cdots$ linear model 


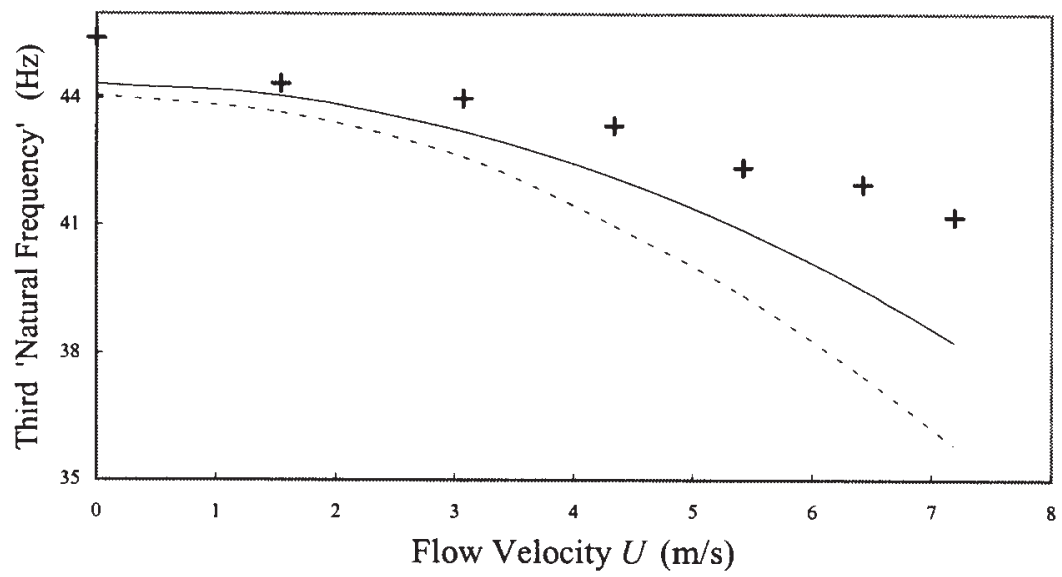

Fig. 9 Comparison of predicted third natural frequency with experiment at $T_{0}=7.63 \mathrm{~N}$ : + experimental result; — present model; $\cdots \cdots$ linear model

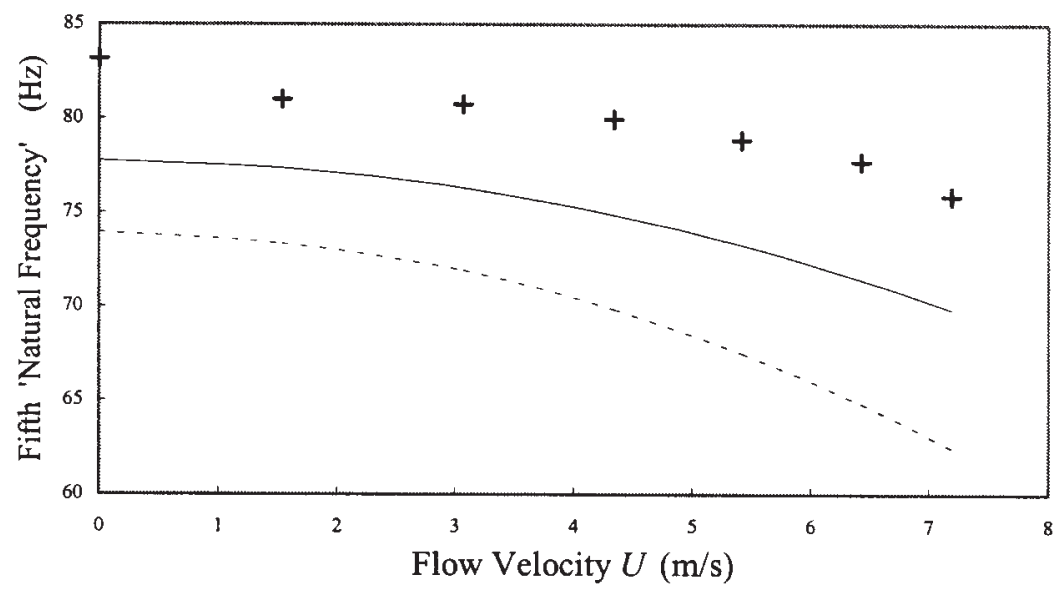

Fig. 10 Comparison of predicted fifth natural frequency with experiment at $T_{0}=7.63 \mathrm{~N}$ : + experimental result; — present model; $\cdots \cdots$ linear model

and experimental conditions. The experimental model exhibited some non-ideal end-supported conditions. The temperature of the water within the pipe may also change with time.

In general, the results of the present model in the linear range appear to agree better with experimental natural frequencies than do the simple linear model results. The authors intend to extend this work to consider more complex flows and include total Lagrangian formations. Future results will be compared with results using the present model.

\section{CONCLUSIONS}

A finite element model has been developed and tested for a liquid-conveying pipe, supported at both ends, using the Lagrange principle, Ritz method and the concept of fictitious loads based on the in-plane kinematic corrections. This model can be applied to the non-linear behaviour of fluid-conveying pipes either undergoing large amplitude vibration and/or exhibiting shear defor- mation and/or rotary inertia effects, or can be used to analyse simple linear conditions. Vibration problems of initially stretched pipes conveying fluid are also examined. At various initial axial tensions of the pipe and flow velocities the numerical predictions of the first, third and fifth natural frequencies using this vibration model in its linear regime have been compared with corresponding experimental results. The results are in good agreement.

\section{REFERENCES}

1 Païdoussis, M. P. and Li, G. X. Pipes conveying fluid: a model dynamical problem. J. Fluids and Struct., 1993, 7, 137-204.

2 Long, R. H. Experimental and theoretical study of transverse vibration of a tube containing flowing fluid. J. Appl. Mechanics, 1955, 77, 65-68.

3 Handelman, G. H. A note on the transverse vibration of a tube containing flowing fluid. Q. Appl. Math., 1955, 13, 326-330.

4 Naguleswaran, S. and Williams, C. J. H. Lateral vibrations 
of a pipe conveying a fluid. J. Mech. Engng Sci., 1968, 10, 228-238.

5 Stein, R. A. and Torbiner, W. M. Vibrations of pipes containing flowing fluids. J. Appl. Mechanics, 1970, 37, 906-916.

6 Chen, S. S. and Rosenberg, G. S. Vibrations and stability of a tube conveying fluid. Argonne National Laboratory Report ANL-7762, 1971.

7 Païdoussis, M. P. and Laithier, B. E. Dynamics of Timoshenko beams conveying fluid. J. Mech. Engng Sci., 1976, 18, 210-220.

8 Païdoussis, M. P., Luu, T. P. and Laithier, B. E. Dynamics of finite-length tubular beams conveying fluid. J. Sound and Vibr., 1986, 106, 311-331.

9 Lee, U., Pak, C. H. and Hong, S. C. The dynamics of piping system with internal unsteady flow. J. Sound and Vibr., 1995, 180(2), 297-311.

10 Dodds, H. L. and Runyan, H. Effect of high-velocity fluid flow in the bending vibrations and static divergence of a simply supported pipe. National Aeronautics and Space Administration Report NASA TN D-2870, June 1965.

11 Holmes, P. J. Pipes supported at both ends cannot flutter. J. Appl. Mechanics, 1978, 45, 619-622.

12 Rousselet, J. and Herrmann, G. Dynamic behaviour of continuous cantilevered pipes conveying fluid near critical velocities. J. Appl. Mechanics, 1981, 48, 943-947.

13 Bajaj, A. K. and Sethna, P. R. Effect of symmetry-breaking perturbations on flow-induced oscillations in tubes. J. Fluids and Struct., 1991, 5, 651-679.

14 Edelstein, W. S., Chen, S. S. and Jendrzeczyk, J. A. A finite element computation of flow-induced oscillations in a cantilevered tube. J. Sound and Vibr., 1986, 107, 121-129.

15 Lin, Y. H. and Tsai, Y. K. Nonlinear vibrations of Timoshenko pipes conveying fluid. Int. J. Solids and Struct., 1997, 34(23), 2945-2956.

16 de Arantes e Oliveira, E. R. A method of fictitious forces for the geometrically nonlinear analysis of structures. In Computational Methods in Nonlinear Mechanics, 1974 (The Texas Institute for Computational Mechanics).

17 Kohnke, P. C. Large deflection analysis of frame structures by fictitious forces. Int. J. Numer. Meth. in Engng, 1978, 12, 1279-1294.
18 Semler, C., Li, G. X. and Païdoussis, M. P. The nonlinear equations of motion of pipes conveying fluid. J. Sound and Vibr., 1994, 169(5), 577-599.

19 Bittnar, Z. and Sejnoha, J. Numerical Methods in Structural Mechanics, 1996, pp. 45-52 (ASCE Press, New York).

20 Zienkiewicz, O. C. The Finite Element Method, 3rd edition, 1997, pp. 500-511 (McGraw-Hill, London).

21 Bathe, K. J. Finite Element Procedure in Engineering Analysis, 1982, pp. 449-556 (Prentice-Hall, Englewood Cliffs, New Jersey).

\section{APPENDIX}

\section{Linear vibration model}

A general set of equations governing the geometrically non-linear motion of fluid-conveying pipes is reported by Semler et al. [18]:

$$
\begin{gathered}
\left(m_{\mathrm{f}}+m_{\mathrm{p}}\right) \ddot{w}+m_{\mathrm{f}} \dot{U} w^{\prime}+2 m_{\mathrm{f}} U \dot{w}^{\prime}+\left(p A_{\mathrm{f}}-T_{0}+m_{\mathrm{f}} U^{2}\right) w^{\prime \prime} \\
+E I w^{\prime \prime \prime \prime}-E I\left(3 u^{\prime \prime \prime} w^{\prime \prime}+4 u^{\prime \prime} w^{\prime \prime \prime}+2 u^{\prime} w^{\prime \prime \prime \prime \prime}+w^{\prime} u^{\prime \prime \prime \prime}\right. \\
\left.+2 w^{\prime 2} w^{\prime \prime \prime \prime}+8 w^{\prime} w^{\prime \prime} w^{\prime \prime \prime}+2 w^{\prime \prime 2}\right) \\
+\left(T_{0}-p A_{\mathrm{f}}-E A_{\mathrm{p}}\right)\left(u^{\prime \prime} w^{\prime}+u^{\prime} w^{\prime \prime}+1.5\left(w^{\prime}\right)^{2} w^{\prime \prime}\right)=0 \\
\left(m_{\mathrm{f}}+m_{\mathrm{p}}\right) \ddot{u}+m_{\mathrm{f}} \dot{U}+2 m_{\mathrm{f}} U \dot{u}^{\prime}+m_{\mathrm{f}} \dot{U} u^{\prime}+m_{\mathrm{f}} U^{2} u^{\prime \prime} \\
-E A_{\mathrm{p}} u^{\prime \prime}-\left(m_{\mathrm{f}}+m_{\mathrm{p}}\right) g-E I\left(w^{\prime \prime \prime \prime} w^{\prime}+w^{\prime \prime} w^{\prime \prime \prime}\right) \\
+\left(T_{0}-p A_{\mathrm{f}}-E A_{\mathrm{p}}\right) w^{\prime} w^{\prime \prime}=0
\end{gathered}
$$

Linearizing equations (22) and (23) and neglecting flexural rigidity and gravity terms, a linear vibration model for steady flow is obtained in the form

$$
\begin{aligned}
& \left(m_{\mathrm{f}}+m_{\mathrm{p}}\right) \ddot{w}+2 m_{\mathrm{f}} U \dot{w}^{\prime}+\left(p A_{\mathrm{f}}+m_{\mathrm{f}} U^{2}-T_{0}\right) w^{\prime \prime}=0 \\
& \left(m_{\mathrm{f}}+m_{\mathrm{p}}\right) \ddot{u}+2 m_{\mathrm{f}} U \dot{u}^{\prime}+m_{\mathrm{f}} U^{2} u^{\prime \prime}-E A_{\mathrm{p}} u^{\prime \prime}=0
\end{aligned}
$$

From equations (24) and (25) the eigenvalues of the system can be extracted by standard methods. 